\title{
The Impact of Mobile Phone ApPs in The Agricultural Production
}

\author{
SUAREZ, S. A. \& SUAREZ, A. M.
}

Abstract: This investigation is focus on the utilization of HTML5 technology in platforms for Android, Blackberry and IOS as an accessible media that permits the farmer to obtain the price of agricultural products during a short time, that in such a way the farmer can make opportune decisions about the sale, the plantation and the harvesting of the product. Besides analyzing the socio-economic impact on the rural zones in Colombia, this industry of technology of information and communication would permit competition useful for the farmers with this new technology. Future works will analyze the performance of other apps in proprietary software product based.

Key words: TIC, Agriculture, Mobile phone Application, Vive digital
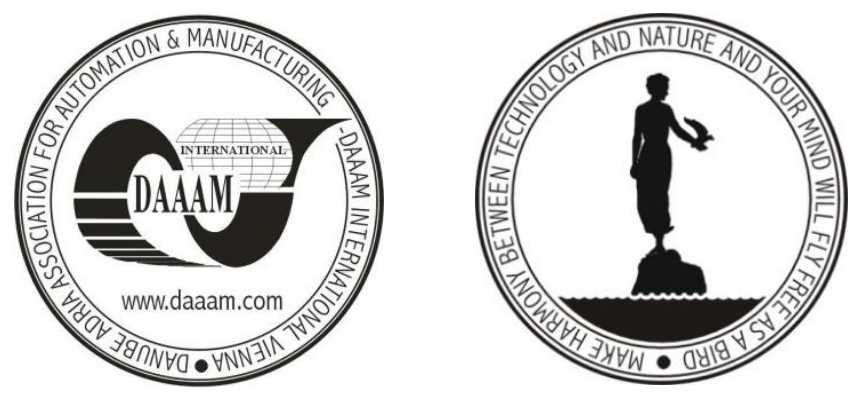

Authors' data: Asist. Prof. Dr. Suarez, S[ir $]^{*}$; Asist. Prof. Dr. Suarez, A[lbert]**, *University of Francisco of Paula Santander Ocana, Sede la granja - Vía al Algodonal, PBX: 5690088, Ocana, Colombia, ** University of Pamplona, Ciudad Universitaria, PBX: 5685303 - 5685304 Ext: 224, 225 Pamplona, Autopista Internacional Vía Los Álamos Villa Antigua - Cúcuta, Colombia, sasuarezc@ufpso.edu.co, alcaldiau@yahoo.com.

This Publication has to be referred as: Suarez, S[ir] \& Suarez, A[lbert] (2013) The Impact of Mobile Phone Apps in the Agricultural Production, Chapter 35 in DAAAM International Scientific Book 2013, pp. 629-636, B. Katalinic \& Z. Tekic (Eds.), Published by DAAAM International, ISBN 978-3-901509-94-0, ISSN 1726-9687, Vienna, Austria

DOI: $10.2507 /$ daaam.scibook.2013.35 
Suarez, S. A. \& Suarez, A. M.: The Impact of Mobile Phone Apps in the Agricultur...

\section{Introduction}

Historically, Colombia is known as an agricultural country, thanks to the diversity of climates and fertile lands. According to the Ministry of Agriculture there are 21.5 million hectares that could be utilized for cultivation (Martincusa \& Gomez, 2010). Among the regions with these characteristics Northern Santander can be found within these territories; nonetheless, this Department presents serious problems in the production and commercialization of agricultural merchandise. On one hand because there is a saturation of goods due to the fact that there is no control for the initial and final dates of planting; on another side of this question there is very little follow-up that could permit the estimation of the time of year when the farmer should plant a determined product.

Thus, stemming from the Departmental Development Plan (Boateng, 2010) the necessity is seen to implement strategies that could aid the improvement of the quality of life for the farmer incrementing his level of earnings and decreasing the price of the basic family table expenditure in the region. To bring about these objective informative and communicative technologies (TIC) should be utilized under the supervision of the project Northern Santander Vive Digital; this plan is part of an initiative of the government that would permit the formation of that bridge between the agricultural sector and the use of the mobile telephone.

It is clear that the use of this technology is widely known thanks to the operators the country counts on thus succeeding with a minimum coverage of $70 \%$; however, the percentage of users that make use of this form to improve their competition is scarce if we compare this to other countries in this region such as; Mexico, Panama, Peru and Honduras (Agüero, 2009), (Brewer, 2005), (Montano, 2007) where 50\% of the rural population has access to these technologies converting the mobile phone into a financial tool for prices and climatology. Besides, the rural population here only uses this equipment to communicate with family members.

In Colombia work that has been done by different institutions and investigators has permitted these processes to be successful, such as; the Information System of the Agro-animal production in the 'Valle de Cauca' (SISAV) whose objective is the integration of resources, personnel and agro-animal production institutions which have been united to share the resources of information. Where the users can accede to the information related to statistical data, production and planted areas in those cultivated lands in the region (Delgado et al., 2006). Other investigations like those of the International Center of Agriculture and the central offices in Palmira of the National University which have tried to standardize this in such a way that Colombia can begin to produce applications to ease agricultural information; this therefore, is the objective of these projects of development of the WEB and the mobile phone to promote that information in the outlying areas where cultivation takes place (AliPate, 2009).

If we speak about international levels, one could name interesting work like the electronic network of the potato which uses cellular telephones and SMS messages to improve commercialization of products. The Hindus use systems of irrigation using the cellular phone by means of a remote system called 'Nano' Gesh; this frees the 
farmer from going great distances to activate the service since the electrical service is irregular and many times this does not permit the farmer to finish his labor. Recently, a study was done about the impact on the social and economic development of the cellular phone in Korea and showed the benefits on agriculture, contributing to the social and economic development of the region (Kyong-jin \& Won-jung, 2012).

Also, in Bolivia a system was successful that permitted the producers and farmers to have access to the information about the prices of goods on the market with benefits to approximately 300 people using the SMS messages and a radial system as a complement (Vasquez, 2012), (Fafchamps \& Minten, 2012), (Donner \& Escobari, 2010). Taking into account the above and with the objective of improving the economic income of the farmers and trying to decrease prices of products in the Northern Santanderean populations in Colombia, an application was developed based on the mobile phone in WAP that permits the farmer to find out prices of agricultural products and at the same time, this gives them the opportunity to offer their goods obtaining the objective that Northern Santander could be converted into one of the regions with a major impact on the commercialization of farm goods at an international as well as at a national level.

\section{Methodology}

The first phase of the project should be limited to the rural zone of Ocana and Abrego; the objective is to know the main advantages and limitations due to the fact that it is a zone presenting common characteristics with the farmers and agriculture in other municipalities thanks to the variety of their plantations. Besides, these two municipalities are within a framework which the National government has centered its efforts through territorial organization within the Province of Ocana. The methodology to be employed would be centered on three basic contexts: qualitative, quantitative and applicative. From the point of view of the qualitative aspect it would be valuable to know the difficulties in obtaining the mobile phone equipment as well as the diffusion of information. On the side of the quantitative aspect the benefits of production must be measured along with prices; while the applicative aspect would be centered on the language, the type of cellular phone and the Internet coverage in the area.

\subsection{Impact of the Cellular Telephone}

The study has been done with the fundamental aspect of type of users: the businessmen and the domestic users. Using polls to permit the gathering of information in this field, besides the open questions where the farmers could express themselves with their own words was the form used. In a general way it was hoped to get to know what the doubts might be, such as:

- What difficulties would the obtaining of a cellular phone be to these farmers?

- If cellular phones have been utilized, what has been the practice used from the point of view of services and markets?

- What has been the difficulties found in the use of these mobile phones? 
Suarez, S. A. \& Suarez, A. M.: The Impact of Mobile Phone Apps in the Agricultur...

- Have they had experiences with colleagues that take advantage of this technology in their productive labours?

At first the methodology now employed by the farmers was not taken into consideration; that of, finding out the prices of products and their source of Information (radio, television, newspapers); that is why these questions must be reformulated using these polls to permit the answers to clear up the differences-benefits of using the cellular phone. The quantitative investigation is focused on a reduced group of farmers trying to maintain the same participants during the period of planting and harvesting; then, the final conditions could be evaluated of the system along with its repercussion on the farmer.

\subsection{Mobile Phone Models}

The variety of equipment that there is of the mobile phone applications, languages to be developed and the prices to buy them, have offered immense possibilities for the development of the application; nonetheless, a problem of the time of implementing the service has been seen; it is this reason that an application must function for the majority of cellular phones. The selection was done taking the advantages and disadvantages as bases, such as the prices of the equipment and the application of free usage. Within the problems found the high cost for the equipment for the rural farmer was an obstacle plus the knowledge of how to use the equipment in its application, the limitations of technology and the limited network of coverage especially within the zone of Abrego. For the prototype of the interface of the cellular phone an analysis was done with the WAP technology which is the protocol that could be used with the mobile phones equipment permitting the communication between the server and the client. These services allow the client to remain informed in 'real time' with alerts where they have been signaled: news, restaurants, reduction of products and marketing campaigns in general. The functionalism is based on the receipt of information from the client through the mobile network which would pass through a WAP Door that is connected to the services found on Internet compounded by a server like WAP and HTML (see Fig. 1).



Fig. 1. Access to Internet using HTML 
Different languages of Extensible Hypertext Markup for example (XHTML), WmLScript similar to Javascript, HTML5; also, those including formats for the access of information. The platform network (Internet) counts on tools that permit the farmer to solicit the price of a product through a specific code; he therefore, can suggest or offer part of them. Besides, it possesses a promoter of contents with real information showing the different prices with the possibility of creating a profile of the user comparing statistics and doing mathematical operations to co-relate values.

\section{Results}

The sample was done with a mixed group of 88 interviews about agricultural leaders in the farm areas which gave an acceptable impression during the first phase. Looking at Table 1 a synthesis can be found of the obtained results of which 53 interviews involved businessmen and 28 involved domestic farm people.

\begin{tabular}{|lc|}
\hline Impact & $(\%)$ \\
\hline General use of Cell Phone & 85 \\
Use of Cell Phone in Rural zone & 73.86 \\
Used by men in Rural zone & 62.5 \\
Used by women in Rural zone & 37.5 \\
Ease to send messages & 86.36 \\
Examples of Phone use & 22 \\
Cell phones with video & 19.31 \\
Coverage of Mobile Network (wifi - paid) & 93.18 \\
Coverage of Mobile Network (wifi-free) & 9.09 \\
\hline
\end{tabular}

Tab.1. The Impact of the Cellular Phone Impact

It can be observed in Table 1 that the penetration of the use of Cellular phones in a general way has reached $85 \%$ of the population; nonetheless, in the rural zone it is reduced in a very slight way even though it maintains a high presence especially to maintain communication with family members and friends. In the rural zone, males tend to maintain a high percentage in its use; this is due to the fact that the production and commercialization is done by the men; however, in a general way there is not too much difference in the use of the Cellular phone by males and females.

One of the disconcerting factors for the application of the technology is the use of the sub-set to send and receive messages; however, a pleasant surprise was received when it was observed that $86.36 \%$ have used some SMS messages to send and receive them. In spite of all this, only $22 \%$ use it as an alternative in order to do business and be informed about prices, offers and the demand of the market due to the unknown ideas and the lack of services dealing with agricultural material. Many of the farmers count on cellular phones that serve them for videos and applications that permit them to manage their products. The coverage and the price of the mobile phone services have been a great inconvenience due to the fact that many accept that coverage exists for the access to Internet but cannot pay the service on time. 
Suarez, S. A. \& Suarez, A. M.: The Impact of Mobile Phone Apps in the Agricultur...

In so far as the productive impact it could be shown that all accepted the technology - see Table 2 where it shows the contribution that could be obtained; nonetheless, it is too early to acquire an acceptable sample due to the short time of implantation of the project that would permit verifiable results to be obtained.

\begin{tabular}{|ll|}
\hline \multicolumn{1}{|c|}{ Impact } & $(\%)$ \\
\hline The implantation of a mobile application & 96.59 \\
That favors the sale of products Prices could be lowered & 100 \\
Monetary earnings & 100 \\
Increase of specific production & 95.45 \\
Decrease of the loss of harvest & 80.68 \\
Possibility of direct sale of products & 62.5 \\
Decrease of trips to find out the variation of prices & 87.5 \\
Low cost of the information service & 77.27 \\
\hline
\end{tabular}

Tab. 2. Impact of Cellular Phone on Production Processes

The majority of the farmers coincide in the importance of the application of the mobile phone operation which could favor the exchange of products and the sale of these thus succeeding in an increment in earnings; however, $19.32 \%$ believe that the loss of a harvest depends on climate factors as well as the offers and internal demands. $95.45 \%$ of those farmers interviewed think that knowing the statistics of the 'real time' could help in the making of decisions for the planting of any one product. One of the inconveniences for the farmers is the sale of the product which is done through intermediates that elevate the final cost to the consumer of the products; this is why $62.5 \%$ hope to sell their products directly to the consumer so that in this way, the social and economic benefits can be successful. Another inconvenience is the means of knowing the prices of the products opportunely; radio and t.v. are generally used and many times trips to the centers of distribution are necessary. This is the reason that $87.5 \%$ comprehend the importance of the application and the benefits proportioned in a real and precise way.

As far as the prices are concerned, it could arise that they affiliate themselves to a system but the farmers presented objections to this form if taxes are applied to the sending of the costs of products; even if these be to obtain information or to share statistics. Practically, three-fourths hoped that this information would be totally gratis; while $22.73 \%$ were willing to pay for a service that would be more concrete but provided that this would result in benefits for their business and for the community. As for the consulting system, an application on the Web could be implemented permitting the farmers to count on a rapid interface and that could be executed on the majority of telephones with the possibility of a connection to Internet. A BLOG also exists that is adapted to the mobile version where the farmer could offer his products along with their prices. The system functions when connected to the page - selection of services and certain pressure dealing with the product which is found in alphabetical order; in this way, the price of the product can be obtained. Also, a code could be sent for this product in such a way that the application used on the SMS for the user would show the data needed (Fig. 2). 

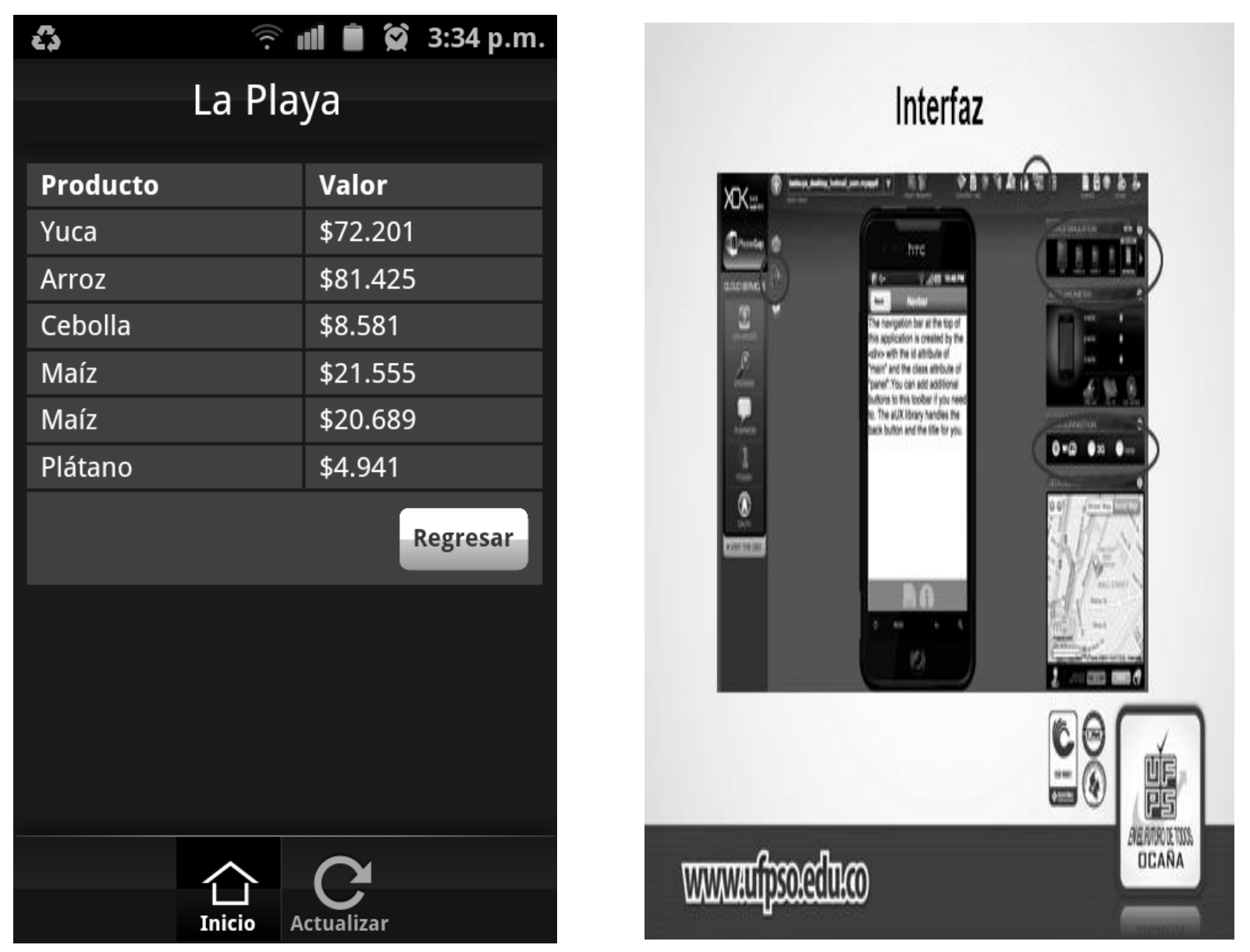

Fig. 2. Information of products based on prices

At this moment the tests have been stopped in order to detect the inconsistencies of the mobile phone connection; however, this is the first phase to be analyzed in this responsibility, acceptance and necessity of the farmer for the implantation of this application whose results show the necessity in this area of agriculture. Later on, in phase II the data will be gotten with those statistics of the use of the platform and the obtained information about the cellular phone.

\section{Conclusion}

It is essential to understand that not only the farmers would be receiving the benefits but that other commerce entities could enter into this use of the cellular phone with the connection dealing with this work. In so far as the appropriation of TIC, it is important to bring out that the methodology based on the development of a simple product would permit the farmer to trust these applications.

Also, the farmers solicited the implantation of means that were more economic, trustworthy and repetitive that would permit the reduction of the production costs, decrease in harvest loss and the value to the family table of their market. This would mean an increment in the farmers' earnings. This is why the combination of the mobile phone on the productive end within the region could be compared to an adequate means to be applied with results in the rural zones. 
Suarez, S. A. \& Suarez, A. M.: The Impact of Mobile Phone Apps in the Agricultur...

Future works will analyze the performance of other apps in proprietary software product based.

\section{Acknowledgements}

Appreciation for this project which has been financed by the University Francisco of Paula Santander in Ocana and the University of Pamplona.

\section{References}

Martincusa, C. \& Gomez, S. (2010). Trade Policy and Export Diversification: What Should Colombia Expect from the FTA with the United States? The International Trade Journal Volume 24, Issue 2, DOI: 10.1080/08853901003652344

Boateng, R. (2010). Enhancing micro-trading capabilities through mobile phones: The case of women traders in Ghana. Information Technology in Developing Countries. Newsletter of the International Federation for the Information Processing, Working Group 9.4 and Centre for Electronic Governance, Indian Institute of Management, Vol 20, No. 1, pg. 2-7, Ahmedabad

Agüero, A. (2009). Education, mobile phone use and production decisions: a rural case study in Peru. En Mobile 2.0: Beyond Voice?. Pre- conference Workshops at the International Communication Association (ICA)

Brewer, E. (2005). The Case for Technology in Developing Regions. Proceedings of the 14th international conference on World Wide Web. ACM (96), New York.

Montano, P. (2007). Information System for the Agricultural Sector of Valle del Cauca (SISAV). Success stories in the use of ICT for agricultural research and innovation in Latin America and the Caribbean, (29-36), San José: IICA, FORAGRO Delgado, J.; Giraldo, C.; Millán, A.; Zuñiga, C. \& Abadía, J. (2006). Developing a Web and Mobile software for managing information field crops Success stories in the use of ICT for agricultural research and innovation in Latin America and the Caribbean (AgrocomM). Systems \& Telematics, pag. 113-124

Ali-Patel, M. (2009). Indian farmers control water pumps by mobile pone. http://www.springwise.com

Kyong-jin, J. \& Won jung K. (2012) Implementation of Mobile Application about Poly Context USN DataMining and Display International Journal of Multimedia and Ubiquitous Engineering, Vol.7, No.3, July

Vasquez, V. (2012). Priorities and policies for ICT use in the Bolivian agricultural sector. Newsletter, eLac2014, No. 18. Pag. 6-7. January

Fafchamps, M. \& Minten, B. (2012). World Bank. India Economic. Impact of SMSBased Agricultural Information on Indian Farmers. Vol. 26, No.3, pag. 383-414 doi:10.1093/wber/lhr056

Donner, J. \& Escobari, M. (2010). A review of evidence on mobile use by micro and small enterprises in developing. Journal of International Development, Vol. 22, pag. 641-658. doi: 10.1002/jid.1717 